\title{
Clip with thread attachment prior to incision - new strategy for traction-assisted esophageal endoscopic submucosal dissection
}

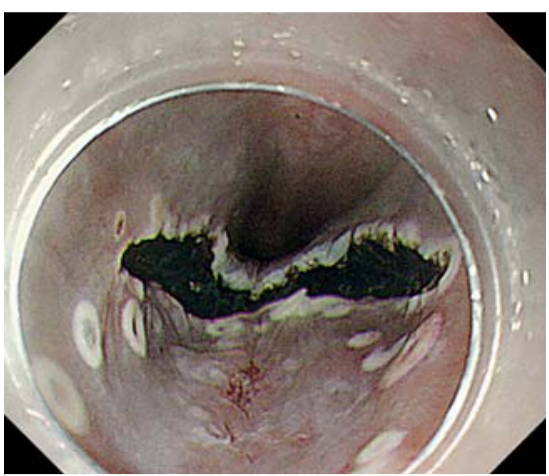

- Fig. 1 Initial incision of anal mucosa of the tumor.

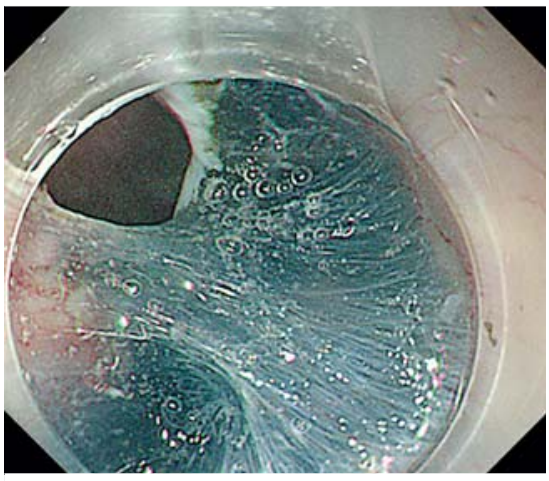

Fig. 4 Dissection of the submucosal area under good traction.

A 55-year-old had a 20-mm 0-Ilc lesion located in the middle thoracic esophagus. Endoscopic submucosal dissection (ESD) was performed using an electrosurgical knife (Flush Knife BT; Fujifilm Corporation, Tokyo, Japan). First, the mucosa of the anal side of the tumor was cut after submucosal injection of $0.4 \%$ sodium hyaluronate ( $\mathbf{F i g . 1}$ ). Subsequently, the oral mucosa of the tumor was adequately elevated by submucosal injection. A clip attached with dental floss was then deployed to the elevated mucosa ( $\mathbf{F i g} \mathbf{2}$ ) prior to incision of the oral-side mucosa

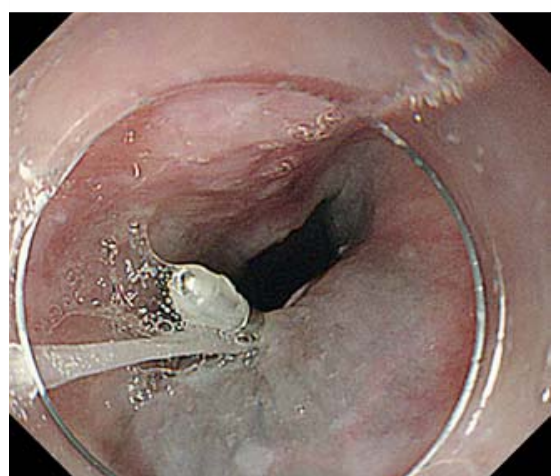

Fig. 2 Attaching the clip with thread to the oral side of the tumor mucosa after elevation by injection.

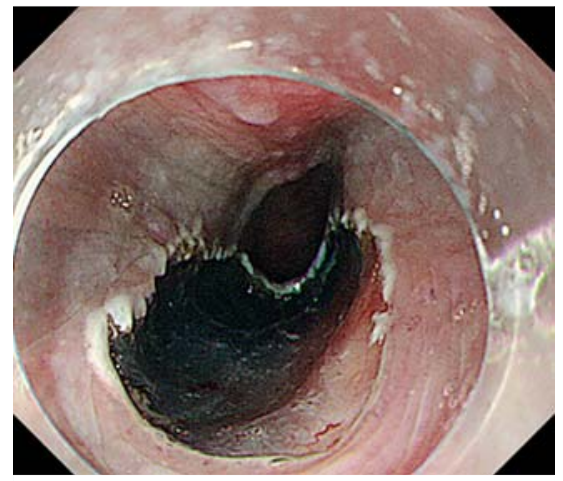

Fig. 5 The esophageal lesion resection en-bloc.

( $\triangleright$ Video 1). The oral-side mucosal incision was performed under ideal countertraction ( Fig.3), facilitating entry to the submucosal layer with sufficient countertraction throughout the ESD procedure. Dissection and the remaining circumferential incision could then be performed with excellent traction ( $>$ Fig.4), enabling this lesion to be resected easily en-bloc ( $\mathbf{F i g} \mathbf{5}$ ).

Previous studies have demonstrated that traction using a "clip with thread" method can make ESD easier and safer [1 -3]. The main strategy in these studies is con-

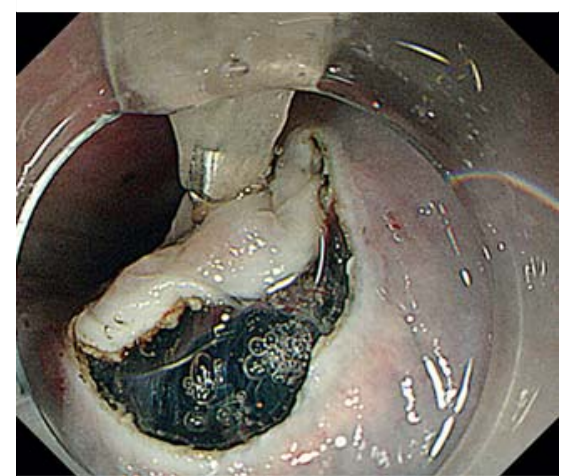

Fig. 3 Ideal mucosal incision created with the clip and thread, facilitating submucosal entry and dissection.

necting the clip with thread to the mucosa after creating a mucosal flap by incision and dissection. However, creating the initial mucosal flap is technically difficult, and there is a risk of attaching the clip to the muscle layer of the esophagus. Ide et al. also reported that clipping prior to the initial incision was convenient for colorectal ESD [4,5]. This strategy of clipping with the thread prior to the initial incision has some merit because it eliminates the need for a mucosal flap. In addition, we can create the opening for the submucosal dissection area with our initial incision and thus dissect under traction easily and safely.

We propose that this new strategy of traction-assisted ESD is a suitable method for esophageal ESD.

Endoscopy_UCTN_Code_TTT_1AO_2AG

\section{Competing interests}

The authors declare they have no conflict of interest 


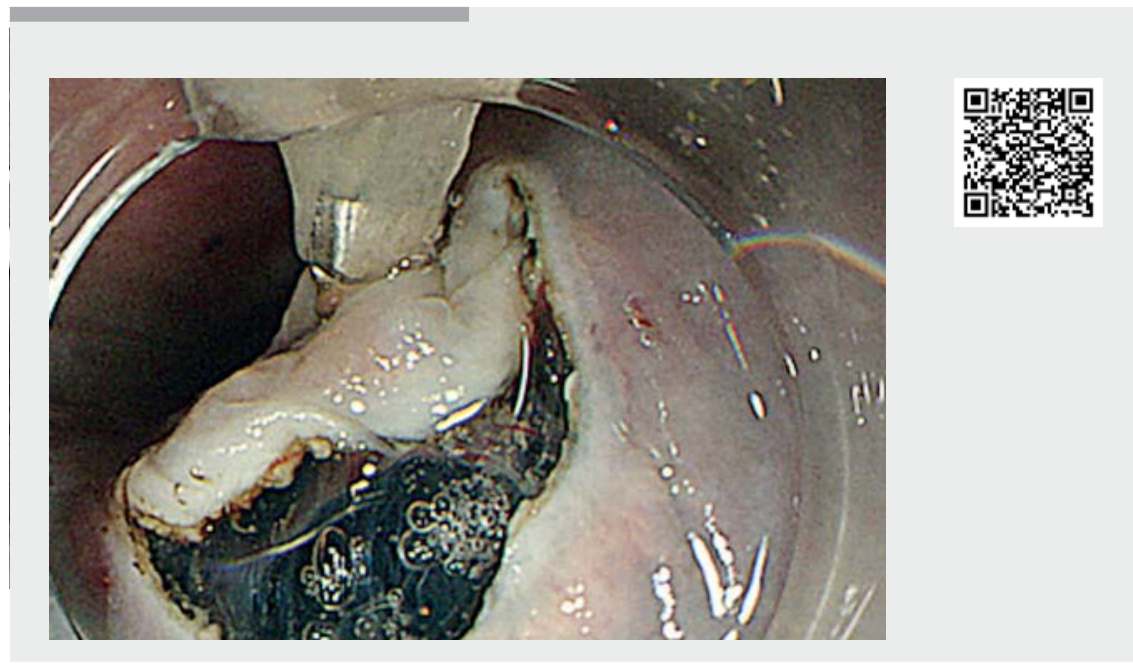

Video 1 A new strategy for traction-assisted endoscopic mucosal dissection of esophageal tumors.

The authors

Shuichi Miyamoto ${ }^{1,2}$, Tomohiko R. Ohya ${ }^{3}$, Masayuki Higashino', Kazuteru Hatanaka', Yoshiya Yamamoto ${ }^{1}$, Hirohito Naruse ${ }^{1}$, Naoya Sakamoto ${ }^{2}$

1 Department of Gastroenterology and Hepatology, Hakodate Municipal Hospital, Hakodate, Japan

2 Department of Gastroenterology and Hepatology, Hokkaido University Faculty of Medicine and Graduate School of Medicine, Sapporo, Japan

3 Department of Endoscopy, The Jikei University School of Medicine, Tokyo, Japan
[3] Xie X, Bai JY, Fan CQ et al. Application of clip traction in endoscopic submucosal dissection to the treatment of early esophageal carcinoma and precancerous lesions. Surg Endosc 2017; 31: 462-468

[4] Ide D, Saito S, Chino A et al. Submucosal pocket creation using a traction device in colorectal endoscopic submucosal dissection. Ann Gastroenterol 2018; 31: 380

[5] Ide D, Saito S, Ohya TR et al. Colorectal endoscopic submucosal dissection can be efficiently performed by a trainee with use of a simple traction device and expert supervision. Endosc Int Open 2019; 7: E824-E832

Bibliography

DOI https://doi.org/10.1055/a-1122-8269

Published online: 4.3.2020

Endoscopy 2020; 52: E328-E329

(c) Georg Thieme Verlag KG

Stuttgart · New York

ISSN 0013-726X

\section{Shuichi Miyamoto, MD}

Hakodate Municipal Hospital, Department of Gastroenterology and Hepatology, 1-10-1, Minato-cho, Hakodate, 041-8680, Japan Fax: +81-138-43-4426

shuichi0210miyamoto@yahoo.co.jp

\section{References}

[1] Koike Y, Hirasawa D, Fujita N et al. Usefulness of the thread-traction method in esophageal endoscopic submucosal dissection: randomized controlled trial. Dig Endosc 2015; 27: 303-309

[2] Oyama T. Counter traction makes endoscopic submucosal dissection easier. Clin Endosc 2012; 45: 375-378

\section{ENDOSCOPY E-VIDEOS}

https:|/eref.thieme.de/e-videos

回回 Endoscopy E-Videos is a free access online section, reporting techniques in gastroenterological endoscopy. All papers include a high quality video and all contributions are freely accessible online.

This section has its own submission website at https://mc.manuscriptcentral.com/e-videos

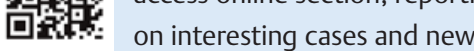

